two pressures; by recording molar changes as so many $\mathrm{kJ}$ rather than as so many $\mathrm{kJ} \cdot \mathrm{mol}^{-1}$; and by hiding so effectively the difference (for example) between an enthalpy change $\Delta H$ and the corresponding standard enthalpy change $\Delta H^{\circ}$. Nevertheless the book can be recommended wholeheartedly to teachers and undergraduates.

In Chemical Thermodynamics, Peter Rock evidently sets out to give a complete account of the subject suitable for use throughout an honours degree. Those tempted to adopt the book should first try to find in it the answers to some crucial questions. What exactly is the difference between $\Delta G$ and $\Delta G^{\circ}$ for a reaction involving real substances? How could one measure in a real laboratory the entropy change consequent on mixing two real gases at constant temperature and pressure? How can the definition: "The standard state of a gas is the hypothetical ideal gas at one standard atmosphere and the temperature of interest" be used to recover the necessary equation:

$$
\begin{aligned}
\mu_{\mathrm{B}}^{\circ}(\mathrm{g}, T)=\mu_{\mathrm{B}} & \left(\mathrm{g}, T, p, y_{\mathrm{B}}, y_{\mathrm{C}}, \cdots\right) \\
& -R T \ln \left(y_{\mathrm{B}} p / p^{\circ}\right) \\
& -\int_{0}^{p}\left(V_{\mathrm{B}}-R T / p\right) \mathrm{d} p,
\end{aligned}
$$

where $\mu_{8}^{\circ}(\mathrm{g}, T)$ is the standard chemical potential at the temperature $T$ of a gaseous substance $B$ having chemical potential $\mu_{\mathrm{B}}\left(\mathrm{g}, T, p, y_{\mathrm{B}}, y_{\mathrm{C}}, \cdots\right)$ at the temperature $T$, pressure $p$, and mole fractions $y_{\mathrm{B}}$ of $\mathrm{B}$, $y_{\mathrm{C}}$ of $\mathrm{C}$ etc.; $p^{\circ}$ is a standard pressure (such as "one standard atmosphere"), and $V_{B}$ is the partial molar volume of the substance $\mathrm{B}$ in the gaseous mixture at $T, p$, $y_{\mathrm{B}}, y_{\mathrm{C}}$ etc.? Still, the book is a good deal better than most of its many shelf-mates.

Three Phases of Matter is a substantially revised edition (". . . around eighty per cent of the English and thirty per cent of the physics has been rewritten') of a textbook which first appeared in 1976. The book is eminently suitable for the introduction of young scientists - whether potentially chemists, biologists or physicists - to the subject that used to be called "Properties of Matter", which, though for no very good reason except that of old-fashioned exposition, had acquired a reputation for being old-fashioned and dull when presented under that name. It contains excellent accounts of the properties of gases and of solids, and an inevitably less satisfying discussion of the properties of liquids (though this section is illuminated by mention of what we have recently learnt from simulation studies). It is a shame, however, that such a book should nowadays contain nothing about the nonanalyticity of the free energy of a fluid (or of a solid) in the immediate neighbourhood of a critical point, and the consequences of that.

M.L. McGlashan is a Professor in and Head of the Department of Chemistry at University College London.

\section{Oceanography: from the deep to the shallows}

\section{Henry Charnock}

Introductory Dynamical Oceanography, 2nd Edn.

By Stephen Pond and George L. Pickard. Pergamon: 1983. Pp.329. Hbk £25, \$45; pbk f6.95, \$12.50.

Physical Oceanography of Coastal

Waters.

By K.F. Bowden.

Ellis Horwood: 1983. Pp.302.

£27.50, \$68.95.

Environmental Oceanography: An Introduction to the Behaviour of Coastal Waters.

By Tom Beer.

Pergamon: 1983. Pp.262. Hbk f15, \$30; pbk $£ 6.50, \$ 13$.

WE HAVE here three new textbooks on physical oceanography, for although Pond and Pickard is an old friend (the first edition appeared in 1978) the present version is much changed in appearance. The smaller page size and the easy-to-read print make a surprising difference: the first edition was reproduced from a typescript, which made the largish pages seem crowded and difficult to read quickly.

There are about 90 more pages but the content is what matters more, of course, and that remains of a high standard - well written, authoritative and managing to convey the fascination to be obtained from applying fluid dynamics to the movement of the ocean. The authors were especially good on scaling and the circumstances in which the full equations of motion can be rationally simplified. Included now is new work on the classical problem of determining ocean currents from observations of the density field and, surprisingly perhaps, a section on eddyresolving numerical models: the use of such models strains the capacity of the largest computers and their interpretation requires a knowledge and an understanding of the observed characteristics of the ocean. The authors refer to other books for the observational background but a combined treatment at a similarly introductory level would obviously be desirable (though it would take a much larger volume). More illustrations would also help, but that apart it is difficult to see how the book could be better.

Professor Bowden's Physical Oceanography of Coastal Waters is based on observation, linked and interpreted by theory expressed in relatively simple mathematics. Intended as a text for undergraduates as well as graduates, it assumes the sort of basic background which Pond and Pickard provide. The latter deal mainly with the deep ocean, but Bowden has tackled the more taxing problems of the shallower coastal waters in which conditions are complicated by larger tides, more friction, complicated physiography and freshwater run-off.

This text is one of the very few to bridge the gap between the many books dealing with the physics of the deep ocean and the handful discussing estuaries. It gives clear accounts of the major topics - waves, tides and surges, currents, temperature distribution and mixing processes - which are authoritative without being too specialized, though readers who need the details will have to pursue some of the many references. The book is an altogether encouraging start to a new series in marine science.

In Environmental Oceanography Tom Beer attempts an even more difficult task, that of introducing the physics of the marine environment to the graduate from a non-scientific background. He intends his book to be used by environmental managers, environmental administrators and students aspiring to such posts (though why they should be drawn from a nonscientific background is not clear).

The book is based on lectures which must themselves have been very stimulating, ranging from fractals to seasickness remedies, and from satellite remote-sensing to a checklist of gear for a coastal environmental investigation. The resulting book seems to me to be less successful, however, containing many interesting sections but lacking integration and coordination. Some statements are incomplete, even plain wrong, and while the errors may not be too serious they make it impossible for this book to be recommended without considerable reservation. Some of my best friends are environmental administrators, and though they may be amused to read that "The Severn bore. . . is the best known bore in the Englishspeaking world" they would be mildly insulted to be told that "The symbol $\pi$ (pi), which represents the number $3.142 \ldots$. is the ratio of the area of any circle to its circumference", and perhaps concerned to read "if 5 tonnes of cyanide is thrown into $100 \mathrm{~m}$ of water, how long before its concentration drops below the recommended $5 \mu \mathrm{g}^{-1}$ ? The main difficulty in answering this question is getting all the physical quantities into the same units".

These are all slips, taken out of context. But there are more serious criticisms, for example of the treatment of the tidegenerating forces and of the radiation balance of the sea surface which physical oceanographers will find off-putting. If the author could have brought himself to leave out some of the more entertaining but peripheral matter, and to combine the accounts of fundamental material into a coherent whole, his book would have been widely welcomed.

Henry Charnock is Professor of Physical Oceanography at the University of Southampton. 